\section{THE PATHOGENESIS OF POLIOMYELITIS}

By Harold K. Faber, M.D. Pp. xvi + I 57, with 16 illustrations. Oxford: Blackwell Scientific Publications. 1955. 36s.

In this small monograph the personal researches of a well-known worker on the poliomyelitis viruses are ably presented. He believes that infection of the central nervous system takes place by way of the peripheral nerves. After infection of the peripheral ganglia there is a secondary excretion into the intestine, followed by re-invasion. He does not believe that there is an initial viremia. His opinions, although interesting, are far from being universally accepted.

\section{THE BOKE OF CHYLDREN}

By Thomas Phaire. Pp. 76 . Edinburgh : E. \& S. Livingstone Ltd. 1955. $7 \mathrm{~s} .6 \mathrm{~d}$.

Ther wasse an worthie leech asked to reviewe

' 'The Boke of Chyldren,' wich thyng nowe he doe And startes wyth murie sperit ande with penne

To shew to DOCTOURS, and eke othre men

How theye mai reade of scabbynesse and ytche,

Of wynde in eares and tinklyng, alle of whiche

Are writ in lettres bold by THOMAS PHAIRE:

He tretes of ylles yt may be cured by hayr

Of hogges, ground yn an asses-greace oyntment

Wt betony, yt do most excellent

To stoppe consumpscioun, brustyng or ye chingles

For yn this boke manye symptom mingles.

Thogh tretement may bee straunge by owre standard

To bettre hys descripsciouns wold be herde

As when he telles of divers sortes of worme.

Hys yllnesses are nevre caused by germe,

But unto evill humours he ascribes

Al sicknesses from apostumes to kybes.

Ye watching chylde was problem then as nowe

And shold be nursed and carryd to allowe

That bellyeful of milke may bee digest,

Wich thyng done, both paraunt and chyld may reste.

Here then, a moste intriguing lyttel boke,

At wich ye wearye PHYSICIOUN maye looke

When from his daylye laboures he feeles soure,

And wold relacks for space of half an houre.
Medical Research Council Memorandum No. 32

\section{THE DIAGNOSIS AND TREATMENT OO HAEMOPHILIA AND ITS RELATED CONDITIONS}

By R. G. Macfarlane, M.D., and R. BigGs, M. Pp. viii + 23. London: Her Majesty Stationery Office. 1955. 2s. 6d.

The preface stresses that although haemophilia the most important of the group of haemorrhagie disorders caused by defective clotting of the blood, is not a common condition, it gives rise to a pressing social problem. The memorandum was written b two of our leading experts in this field on behalf of the Haemophilia Committee of the Medic Research Council.

In the introduction the present concept of coagulation is given:

r. Antihaemophilic globulin + Plate Christmas factor

Intermediate product.

Factor V

2. Intermediate product + Factor $\mathrm{V}$ Factor Thromboplastin.

3. Prothrombin $\stackrel{\text { Thromboplastin }}{\longrightarrow}$ Thrombin. Thrombin

4. Fibrinogen $\longrightarrow$ Fibrin.

The incidence of haemophilics in this country believed to be $\mathrm{I}$ to 2 per 100,000 .

The chapter on clinical diagnosis emphasises the value of a good history and the drawing up of -9 family tree which should cover at least thre generations. Haemophilia should be distinguisheg from purpura and acquired clotting defects as well as from vascular disturbances.

Laboratory diagnosis should include platel counts, bleeding time, tourniquet tests and a whole blood clotting time. Conditions with an abnorma one-stage prothrombin time are fibrinopenia, pro thrombin deficiency, factor $\mathrm{V}$ deficiency, and factor VII deficiency. The group with a normal one stage prothrombin time contains haemophilie Christmas disease and the presence of circulating anti-coagulants.

The chapter on technique deals with the prepard tion of special reagents, preliminary tests and $: a$ description of the thromboplastin generation test

The last section, on treatment, states that the 
treatment of coagulation defects is still, unfortunately, far from satisfactory. Fresh blood, not more than three hours old, in really large quantities, is probably the only useful way to restore the antihaemophilic globulin level to the necessary 30 per cent. in severe cases of haemophilia. The local treatment and that of haemorrhages from special sites is briefly sketched.

This booklet is just about the best half-crown's worth on this subject for many years.

\section{MODERN OPERATIVE SURGERY}

Edited by the late G. Grey Turner, LL.D., D.Ch., M.S., F.R.C.S., F.R.A.C.S., F.A.C.S. and LAMBert Charles Rogers, V.R.D., M.D., M.Sc., F.R.C.S., F.R.C.S.E., F.R.A.C.S., F.A.C.S. Fourth Edition, Volume I. Pp. xx + I229, with 476 illustrations. London: Cassell \& Co. Ltd. I 955 . 70 s.

The object of this work as expressed in the preface of the first edition was to survey the " whole range of modern surgical operations.' Throughout the editions this object has been achieved and this latest edition is no exception. It is pleasing therefore to see chapters on orthopaedic, thoracic and neurosurgery included in the text. This necessitated the co-operation of many authors and the list of contributors is impressive.

This is a thoroughly good book which can be whole-heartedly recommended. Some important chapters (e.g. mouth, oesophagus) have been omitted but are perhaps included in Volume II. In each chapter the common and important diseases are made quite obvious and given due emphasis. One regrets that a larger format was not adopted as it would have made the setting out neater; but the text is very well written and indeed invites reading. The contents are logically set out and, with the excellent index, reference to a particular subject is easy. The illustrations are mostly drawings which have the great quality of making perfectly clear the particular point to be illustrated. Many good clear diagrams have also been used.

Each chapter contains the optimum amount of anatomy and physiology together with indications for operation and complications. Unfortunately the Birmingham Revision of the B.N.A. has not been adopted throughout, so that the discrepancy between anatomical nomenclature as taught and as practised be at last removed.

There is an introductory chapter on the basic surgical principles involved in pre-operative, operative and post-operative techniques which stresses the reasons for performing various manoeuvres all too often taken for granted and their object lost. Excellent accounts are given of the history of some particular operations and their evolution to the modern operation, which further emphasise the underlying principles and facilitate the task of learning.

Furthermore, it allows own personal opinions to be formulated. Dogmatic statements are avoided and on the whole opinions with which the author obviously disagrees are fairly given. In the treatment of breast carcinoma McWhirter's more conservative method is harshly dealt with and his latest figures, together with recent ones from other centres, are not included although many surgeons have accepted them.

That there are some discrepancies is inevitable, and controversies are bound to arise: many surgeons would probably disagree with the advocated treatment of tuberculous collar stud abscess in the neck, and to the surgical student it is a little disarming to find proximal as opposed to distal ligation recommended in certain cases of aneurysm of the innominate artery in one chapter, whilst in the very next one the exactly opposite view is expressed!

On the whole, however, this is an excellent book and will rightly be read and adopted by many. We look forward to Volume II. (j.J.

\section{PSYCHOSOMATICS}

By Max Hamiltox, M.D., D.P.M. Pp. xii +225. London: Chapman and Hall. 1955. 2 Is.

This book is an addition to 'Frontiers of Science' -a series of scientific publications designed to fill the gap between elementary textbooks and specialised treatises, and to meet the needs of scientific readership in all fields of science. To produce a book which will measure up to the standards of its contemporaries on such a subject as Psychosomatics has been a formidable task which the author has completed with great success.

The last 12 months have seen a number of books on this branch of medicine appear on the publisher's lists, and two volumes have been reviewed in these columns quite recently, yet it must be admitted that there is very little overlap between Dr. Hamilton's work and that of his predecessors. Described as a comprehensive and critical summary of the vast quantity of literature and research reports published on this subject, it carefully reviews the experimental work and the theories derived therefrom, and the author makes evident his own bias towards quantitative assessment and statistical evaluation by describing his own published work as being more orthodox than that of certain other investigators. Few would consider this bias a fault.

After an introductory chapter, the author carefully explains the physiology of the emotions, although the non-medical reader will probably wish for a more detailed explanation of the autonomic nervous system and the mechanism of the para- and sympathetic activity to which so many psychosomatic conditions are related. In the following chapters the respiratory, gastro-intestinal, and cardio-vascular systems are treated separately, followed by disorders of the skin, endocrines, and muscles and joints, and concluding with a general summary and conclusions. Each chapter describes studies of personality configurations and possible mechanisms through which the disorder is mediated, and has an individual summary and useful bibliography.

No mention is made of therapy, presumably 